\section{NOTE ON THE MORPHOLOGY OF BLOOD - PLATES.}

MARY W. ROWLEY, M.D. Boston.

Blood plates are usually described as from one to three microns in diameter. The accompanying photographs* demonstrate that they are often much larger than this, with a good deal that suggests cell-structure.

The blood in which the platelets here reproduced were found was from three cases, one of pernicious anemia, one of splenic anemia and one of severe secondary anemia. Using a modification of Wright's method of staining. I have obtained similar plates in cases of malaria, myelogenous leukemia and in normal blood. With this stain the definite, usually rounded outline of the periphery is distinctly shown. In most of the figures hitherto published the edges of the plates are jagged and irregular.

Why are these plates so much larger than those usually described and pictured? Their size is probably due in part to squashing, as there are more large ones near the thin edge of the blood-smear where the leucocytes are also larger. But I believe that another reason is that with ordinary technic only the central deep-stained portion (Fig. 1) is visible at all. The periphery remains unstained and so invisible except when the platelet lies on a red cell. Then the periphery (with ordinary "Romanowsky" stain) usually appears colorless against the pink or yellow of the red cell (Fig. 2 shows a plate lying partly on a red cell with this periphery stained). I believe that with a suitable staining method plates similar to those here figured can be found in all or nearly all blood, normal and pathologic. I am now trying to work out such a staining method.

All of these specimens have been studied by Dr. Richard C. Cabot, who authorizes me to say that he entertains no doubt that the figures here shown are genuine blood-plates.

I am very much indebted to Dr. Cabot for assistance and encouragement given me by him in studying the blood-plates above described.

\section{THE EARLY DIAGNOSIS AND RADICAL CURE OF CARCINOMA OF THE PROSTATE.}

A STUDY OF FIFTY CASES AND PRESENTATION OF A CAL OPERATION. **

HUGH H. YOUNG, M.D.

Associate I'rofessor of Genito-Urinary Surgery of the Johns IIopkins University.

BALTIMORE.

In the October number of the Johns Hopkins Hospital Bulletin I described briefly an operation for the radical cure of carcinoma of the prostate based on a study of forty cases. ${ }^{1}$ Since then I have had ten additional cases. In the paper referred to I discussed first six cases which were seen early in the disease, in which a diagnosis of benign hypertrophy was incorrectly made and a partial operation therefore performed. (Bottini operation, 4; suprapubic prostatectomy, 1; perineal prostatectomy, 1.) All these patients subsequently returned with unmistakable evidence of cancer, and only one is alive to-

* Photographs by Louis S. Brown of the Massachusetts General Hospital.

* Read before the Southern Surgical and Gynecological Association, Louisville, Ky., Dec. 14, 1905.

1. To appear in full in the Johns Hopkins Hospital Reports, a volume entitled "Studies in Urinary Surgery." day. A study of the pathology of these cases, along with the symptomatology and clinical findings, showed that all presented certain features which may now be taken as suggestive of cancer. A study of thirty cases without operation and eight autopsies showed that cancer of the prostate may begin as a small indurated nodule in one or both lobes of an otherwise benign hypertrophy, that it remains confined for a long time within the stout capsule of the prostate, that its line of invasion is upward along the course of the vasa deferentia and seminal vesicles, and not usually into the bladder around the prostatic orifice, and that the inferior surface of the trigone is usually the first portion of the bladder to become involved.

It thus became evident that if a radical cure was to be attempted the line of excision would have to include the entire prostate, with its capsule and urethra, the adjacent portion of the bladder, particularly of the trigone, the seminal vesicles and the ampullæ of the vasa deferentia.

During the course of a year four cases apparently favorable for such a procedure presented themselves, and the operation above indicated was carried out with little difficulty, slight operative shock and a very satisfactory convalescence in three cases; the histories were reported in detail. During the last six months ten patients with carcinoma of the prostate presented themselves, all beyond operative relief but one, and he would not submit to it. In one case, which seemed fairly favorable, the patient was operated on, but died, and autopsy showed extensive involvement of the pelvic peritoneum. In all of these cases the patients had been treated for a long time by their family physicians, and in several instances by skillful surgeons, and the character of the disease was not recognized. Had it been possible to get these cases earlier I believe the radical operation which I have proposed as a routine procedure for all favorable cases of cancer of the prostate would have resulted in cure.

\section{DIAGNOSIS.}

The early diagnosis of cancer of the prostate is not easy. I am free to confess that I have failed in at least six cases, and until confronted by their subsequent development never suspected the malignant nature of the disease. A study of the fifty cases which I have now had has brought out the following facts:

Symptomatology.-Cancer of the prostate may occur at any age after fifty years, 57 per cent. of the patients being between sixty and seventy years of age, the youngest in my series being fifty-three. The first symptoms in most cases were similar to those of benign prostatic hypertrophy, viz., slight difficulty and frequency of urination, but in about 30 per cent. of the cases pain was present-an unusual symptom in cases of prostatic hypertrophy. Hematuria occurred only four times as an early symptom, and in only about 20 per cent. of the cases was it subsequently present, in only a few cases as a prominent symptom; and these cases showed cystoscopically considerable intravesical tumor outgrowth, generally of a villous type. In a few instances the prostatic trouble ran a long course, having been present twenty years in one instance, but in these cases the disease probably became malignant many years after its onset. As a rule there has been a more rapid increase in the severity of obstructive symptoms than in benign cases, leading to an early large residual urine. In some cases, however, there has been little residuum and the bladder has been contracted.

Pain has been a prominent symptom, often entirely 


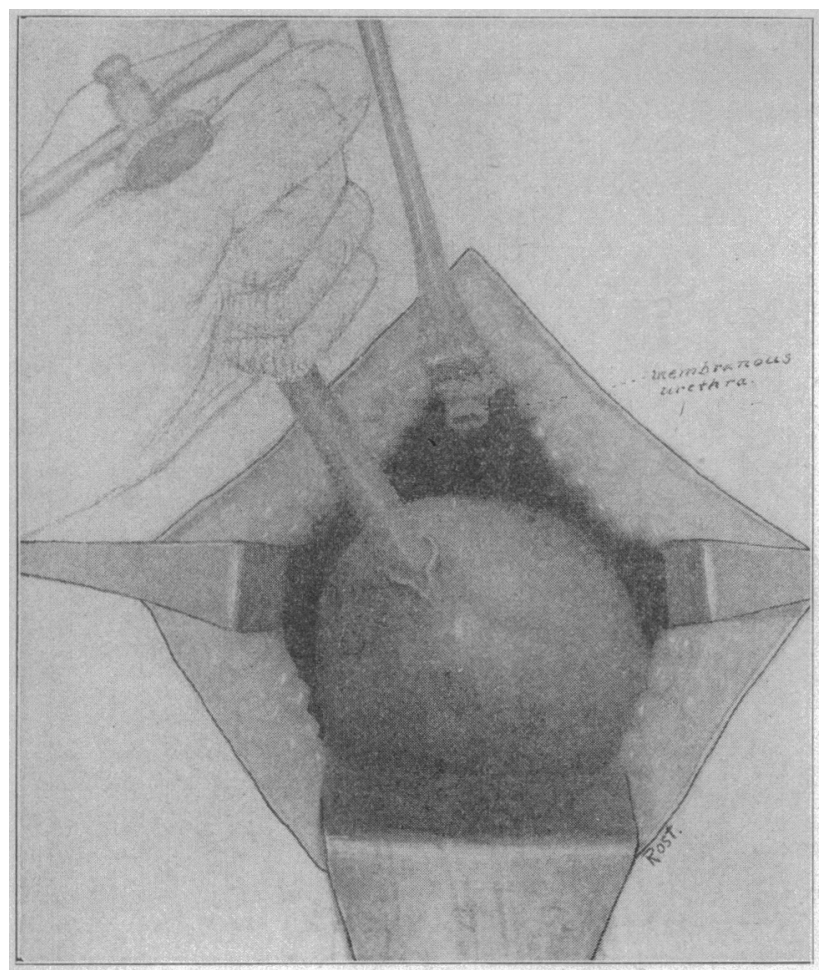

Fig. 1.-Membranous urethra and pubo-prostatic ligaments di vided; prostate freed from surrounding adhesions.

out of proportion to the extent of the disease and the obstruction present. It generally appeared as a dull pain in the suprabubic region, which became worse as the bladder became full. During urination in about 25 per cent. of the cases there was pain in the urethra, often referred to the end of the penis, but sometimes limited to the deep urethra or perineum. Pain in the rectum has been present in only 10 per cent. of the cases, and seems to have no relationship to the extent of the involvement

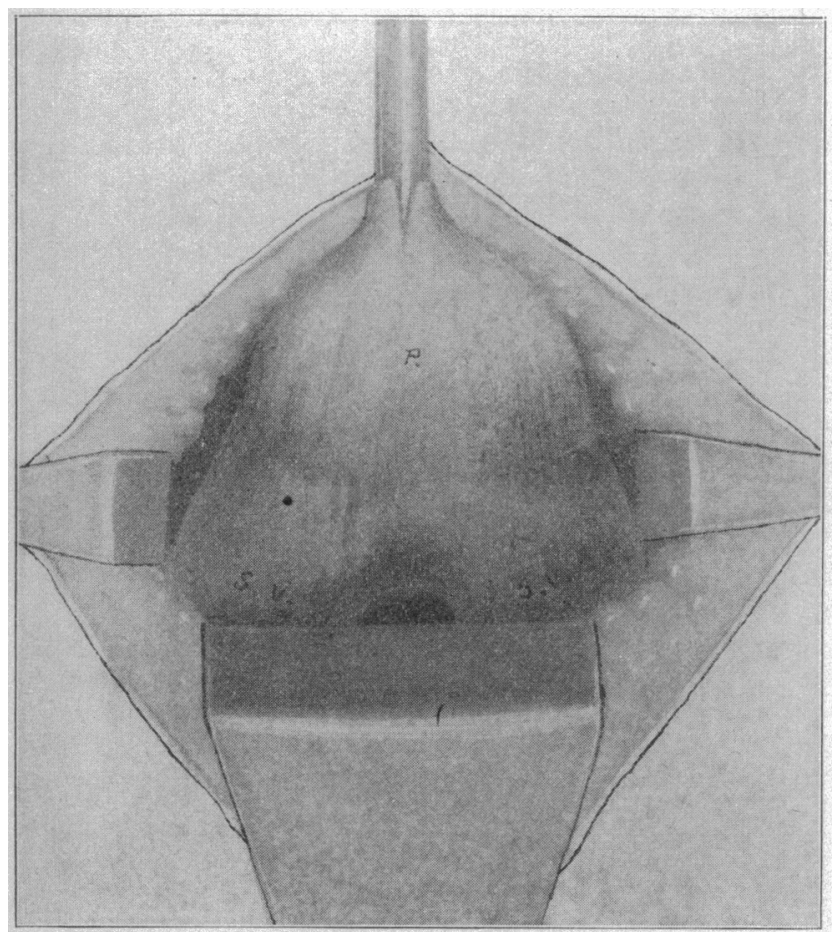

Fig. 2.-Freeing the posterior surface of seminal vesicles. Pros tate drawn well out of wound.

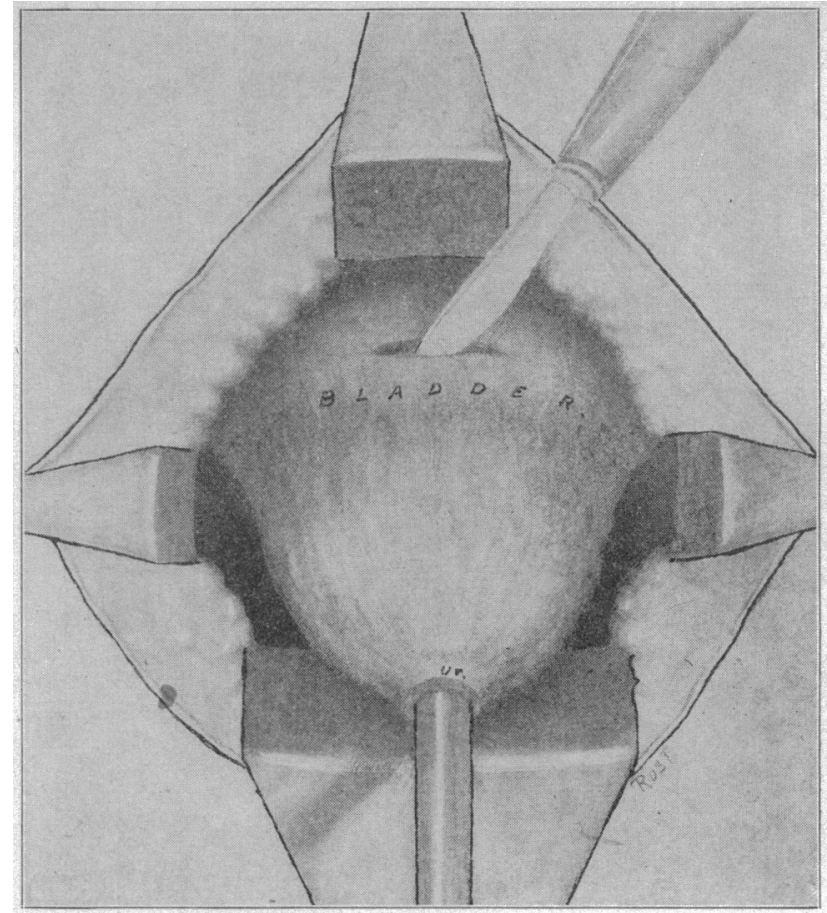

Fig. 3.-Prostate drawn downward exposing anterior surface of the bladder which is incised by scalpel.

in the pelvis, being noticeably absent in a number of cases of extensive prostato-pelvic carcinosis. The same may be said for pain in the lower extremities, hips, thighs, buttocks and along the sciatic nerves; it has been present in cases of slight degree and absent in others of considerable involvement. When present, however, pain in the rectum and lower extremities is a very suspicious symptom and should strongly suggest malignancy. Loss of weight has been a prominent symptom,

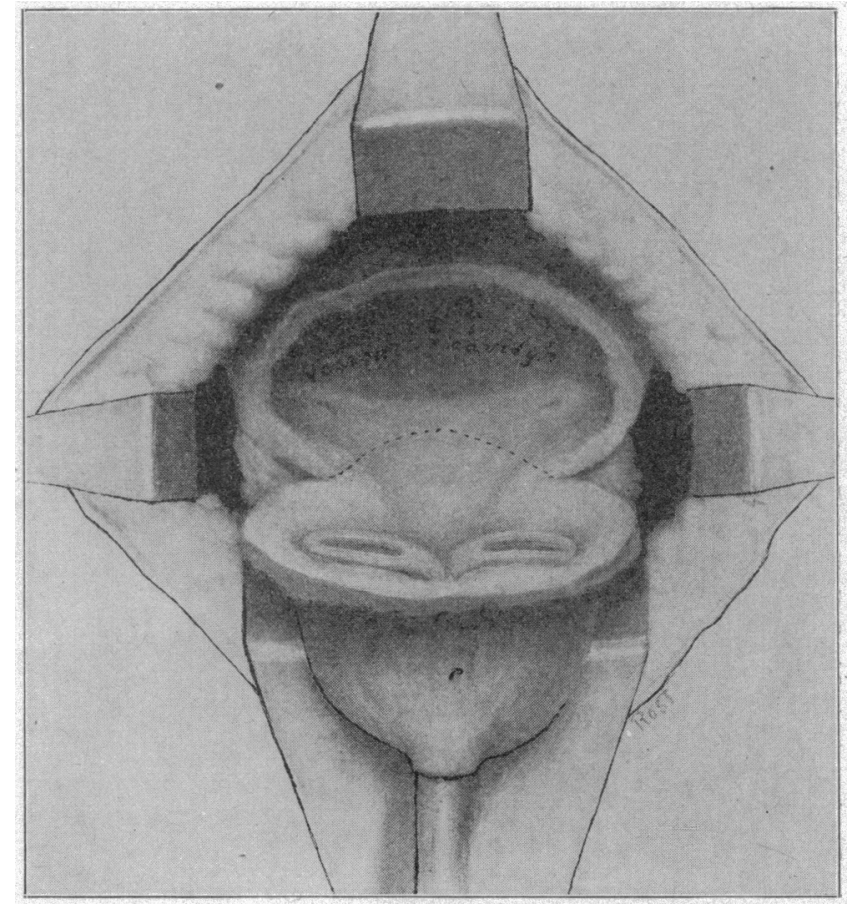

Fig. 4.-Excision of vesical cuff carried as far as trigone. Dot ted line shows site of division through trigone. 


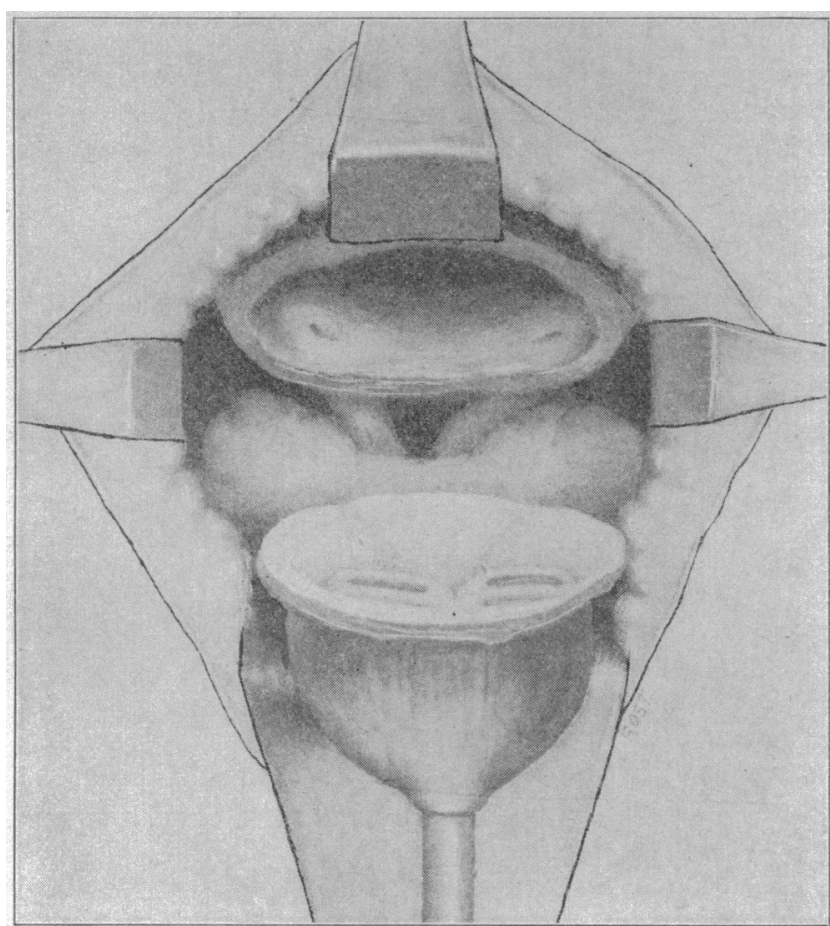

Fig. 5.-Trigone divided. Seminal vesicles and vasa deferentia exposed preparatory to division of rasa.

often occurring early in the disease, and being much more pronounced than in cases of simple hypertrophy.

Clinical Findings.-The prostate was considerably enlarged in about 70 per cent. of the cases, but many of these patients were seen late. When the disease is still confined to the limits of the prostate proper this organ has generally been found only moderately enlarged. In such cases portions of the prostate in a few instances have been soft, but marked induration, generally involving almost all of the prostate, has been found in nearly all the cases. The surface of the prostate was smooth in most instances and only rarely rough or nodular until late in the disease.

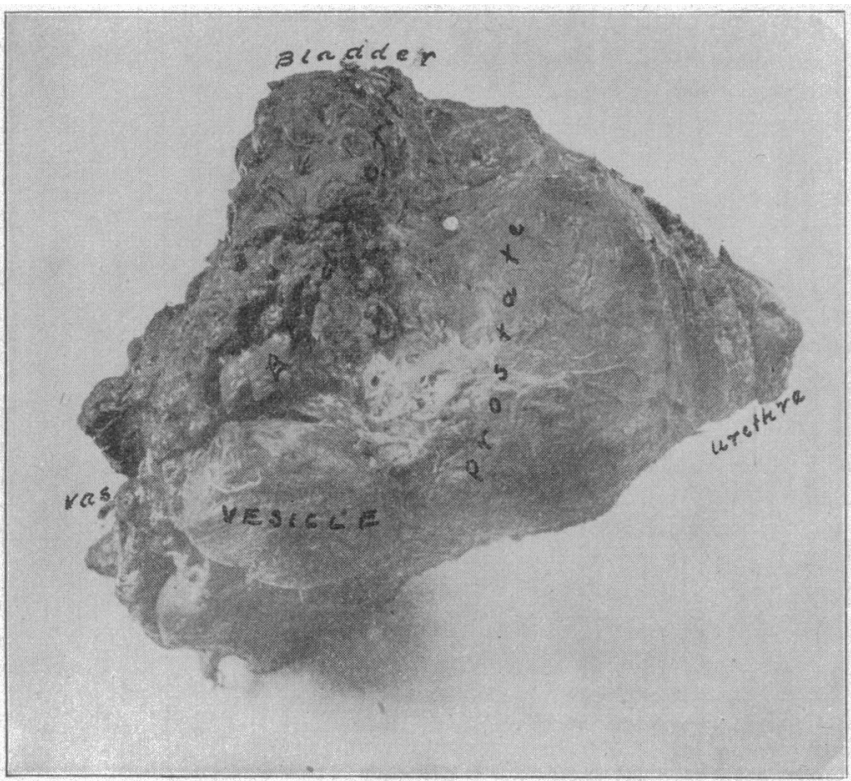

Fig. 6.-Specimen removed; side view.

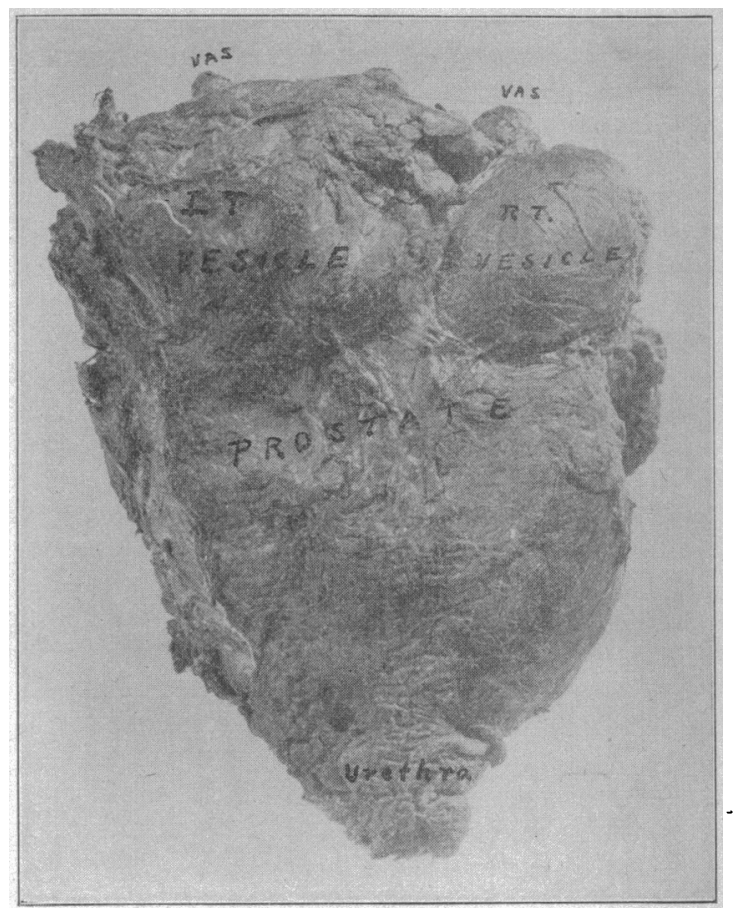

Fig. 7.- losterior view of specimen in ligure 6.

In one early case there was a small prominent rounded induration at the apex of the prostate involving also the membranous urethra. In later cases the region of the seminal vesicles has shown induration, and often a characteristic hard plateau extending across the intervesicular space from one vesicle to the other and presenting a concave sharply defined upper border to the finger has been present. Study of pathologic specimens has shown this is to be composed of a cancerons invasion of the vasa deferentia and the tissues between them and the trigone. An unusual thickness in the retrourethral portion of the

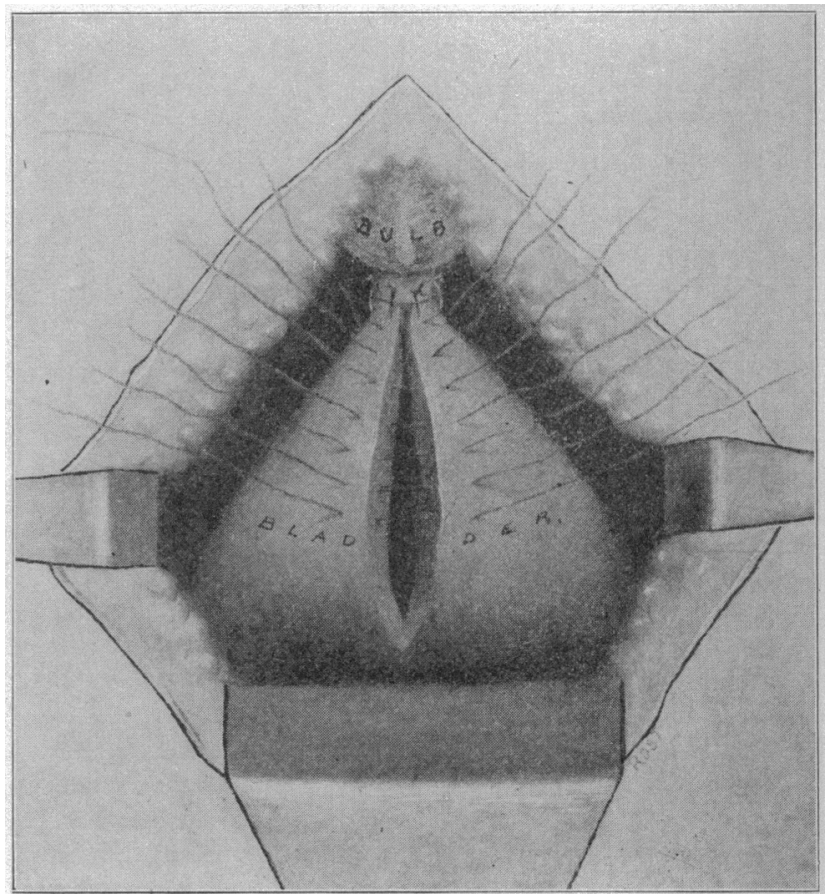

Fig. 8.-The anterior part of the vesical opening has been anastomosed to stump of membranous urethra, remainder being closed by interrupted sutures. 
prostate (the posterior commissure), as shown by an instrument in the urethra and a finger in the rectum, was nearly always present. Enlarged pelvic lymphatic glands have been found in only a small number of even the more advanced cases, and as they are occasionally present with ordinary prostatitis their presence or absence is of little diagnostic or prognostic value, unless they are a prominent feature. A remarkable characteristic of cancer of the prostate is that metastases directly to the osseous system occur more often than to the glands.

The cystoscope las been of the greatest assistance in the diagnosis in early cases, as it has shown a distinct and radical difference in the intravesical picture from that scen in cases of benign hypertrophy. In the latter one usually sees two or three rounded intravesical lobes with deep sulci between and a pronounced bas fond behind them. In most early cases of carcinoma of the prostate practically no intravesical enlargement could be seen, and the entire abscnce of decp intervening clefts has been a constant finding in even the great majority of the advanced cases. Except in those rare cases in

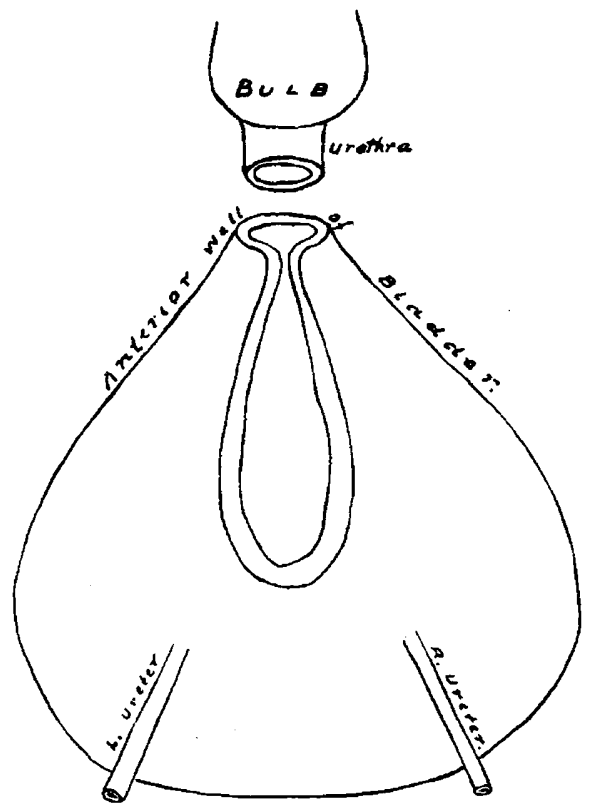

Fig. 9.- Hiagram showing plan of vesico-uretbial anastomosis.

which intravesical tumors were present, if any intravesical prostatic enlargement were visible it was generally only a slight enlargement of the median portion. A picture of diagnostic importance is an elevation and puckering of the mucous membrane of the anterior portion of the trigone-due, as $I$ have found, to the intervesicular mass of disease involving the trigone and leading to its contracture. Ulceration and intravesical tumor formation has been very rare in this region and then only very late in the disease.

Before withdrawing the cystoscope I have always inserted a finger into the rectum, and the finding in malignant cases has nearly always been entirely different from that in benign cases. There has always been a much greater thickness in the retrourethral portion of the prostate, the median portion being especially thick and the consistence very hard. In later cases, in which the disease has passed above the prostate into the retrotrigonal area, it has been impossible to feel the beak of the instrument in the bladder.

Early diagnosis then may be based on a suggestive history (rapidity of growth and pain), an indurated prostate, a strictured condition of the prostatic urethra near its apex, and the absence of intravesical lobes as shown with the cystoscope. All these conditions are rarely present together, but generally enough are discernible to make the diagnosis clear. An induration of the prostate, coming on without recent prostatitis, without catheterism or an infected bladder, in a man past fifty, with symptoms of urinary obstruction, and particularly with pain, should make the physician suspect cancer at once, and a perineal operation should be undertaken to settle the diagnosis. If residual urine in considerable amount is present without the presence of intravesical lobes, as shown by the cystoscope, the suspicion may be considered strengthened. If one is unable, however, to be certain the prostate can be exposed, as for ordinary prostatectomy, and then by inspection and palpation the diagnosis can be made certain in most cases. In some instances I have been uneertain, and have then made bilateral capsular incisions and excised small portions of the lateral lobes for microscopic study. In two cases it was shown that the irregular induration was due to seed calculi of the prostate gland and in two other cases it was necessary to have frozen sections prepared before I could be certain of the nature of the discase. With a surgical pathologic laboratory adjacent it has been possible to get a nicely stained section for microscopic study in six minutes, and I have considered this worth waiting for in several instances. I have proposed, therefore, to follow the procedures above described in all suspicious. cases, and repeat that those cases in which there are areas of stony induration, with pain as a prominent symptom, and little intravesical prostatic enlargement, may be considered very suspicious.

RADICAL OPERATIONS.

As above stated, operations and autopsies have demonstrated that the entire prostate with its capsule and urethra, the seminal vesicles, the ampulla of the rasa deferentia and the superjacent portion of the vesical trigone, must be excised in one piece if radical cures are to be expected.

A study of the literature of cancer of the prostate shows that this operation has not been done before for the disease. I have excluded the case of Kuster, who removed the entire bladder and transplanted the ureter into the rectum, and the case of Harris, who excised most of the bladder with the prostate (seminal vesicles not mentioned) and transplanted the ureters into the vertex of the bladder. Both of these were suprapubic operations and the patients lived five days and five months respectively. Two cases reported by Demarquay and that of Czcrny, in which the anterior wall of the rectum was excised, have also been excluded.

The operation which I have carried out in six cases as a routine procedure for cancer of the prostate is described as follows in the history of one of the cases:

operation.-An inverted $\mathrm{V}$ cutaneous incision was made in the perineum as in the operation employed by me for simple hypertrophy of the prostate, each branch of the incision being about two inches long. By blunt dissection the end of the bulb and central tendon were exposed, and the latter divided, exposing, in turn, the recto-urethralis muscle, the division of which gave free acess to the membranous urethra behind the triangular ligament. Urethrotomy on a grooved staff was followed by introduction of the prostatic tractor, which was opened out after it reached the bladder. While traction was made on this instrument the rectum was carefully separated from the prostatic capsule by blunt dissection until the entire posterior sirface of the prostate was brought into view. Up to this point the operator proceeded exactly as in the usual prostatectomy operation. The tissues around the prostate were more hemorrhagic and the wall of the rectum more 
closely adherent to the capsule of the prostate than usual. Examination of the prostate showed much greater induration than I have ever encountered in the benign prostate. The rectum and periprostatic tissues were free from invasion, and complete excision was, thereforc, decided on and carried out as follows: The handle of the tractor was depressed, thus exposing the membranous urethra anterior to it at a point where it was easily divided transversely with a scalpel, leaving a small stump of the membranous urethra protruding from the surface of the triangular ligament. By further depressing the handle of the tractor the pubo-prostatic ligament was exposed and, being very tautly drawn, was easily divided by scissors, thus completely severing the prostate from all important attachments, except posteriorly (Fig. 1). The lateral ittachments, which are slight, were easily separated by the finger. During these manipulations a moderate amount of hemorrhage was encountered (coming from the periprostatic veins, particularly those just behind the triangular ligament in front of the prostate), but it was easily controlled by clamping several bleeding points and applying pressure with gauze by means of an anterior deep retractor (Fig. 3 ).

The posterior surfaces of the seminal vesicles were then freed by blunt dissection, the now mobile prostate being well out of the wound, as shown in Fig. 2. In this exposure of the posterior surface of the vesicles I was careful not to break through the faseia of Denonvilliers which covers not only the posterior surface of the prostate, but also that of the seminal vesicles, and forms, I believe, an important barrier to the backward growth of the disease. The next step was to expose the anterior surface of the bladder, which was easily done by depressing the tractor and making strong traction. By this procedure the bladder was drawn down close to the skin wound that it was easily incised at a point in the middle line about $1 \mathrm{~cm}$. behind the prostatovesical juncture (Fig. 3).

By means of scissors the division was continued on each side until the trigone was exposed (Fig. 4). After swabbing away the blood and urine, the ureters were easily found and the line of incision carried across the trigone with a scalpel so as to pass about $1 \mathrm{~cm}$. in front of the ureteral orifices. While still making traction on the prostate, the base of the bladder was pushed upward with the handle of the scalpel, thus exposing the anterior surface of the seminal vesicles and the adjacent vasa deferentia (Fig. 5), all of which were carefully freed by blunt dissection with the finger as high up as possible, so as to remove with the vesicles much circumjacent fat and areolar tissues on account of the lymphaties which they contained. The vasa deferentia, after being drawn well down, were picked up on a small blunt hook and divided with scissors as high up as possible, care being taken to see that the ureters were not in danger. After division of the vasa, the seminal vesicles were found to come down more readily, the deep adhesions were finally divided, and the mass shown in Fixs. 6 and 7 was removed. As seen here in the side view, a portion of the membranous urethra, the entire prostate with its capsule intact, the seminal vesicles, $4 \mathrm{~cm}$. of the vasa deferentia, and a cuff of the bladder $1 \mathrm{~cm}$. wide along the anterior and lateral surfaces and $2 \mathrm{~cm}$. wide in the region of the trigone has been removed in one piece.

There now remained a large defect to repair. The vesical opening was about $8 \mathrm{~cm}$. in diameter and had sunk far back in the depths. The stump of the membranous urethra had been obliterated by the compression of the anterior retractor so that it was necessary to insert a soft rubber catheter through the urethra from the meatus to discover it. The anterior wall of the vesical opening was then caught with forceps, and I was surprised to find how ensily it could be drawn down to the membranous urethra, where an anastomosis was rearlily made, as shown in Figs. 8 and 9 . The first suture was placed by inserting the needle into the triangular ligament above the urethra and bringing it out through the anterior wall of the membranous urethre. then through the anterior wall of the hadder in the median line from within ont, care being taken to include only the submucosa and muscle. When thi suture was tied, the median line of the anterior wall of the bladder was drawn to meet the median line of the roof of the remaining membranous urethra; the knot was outside, and the thread was left long.
Lateral sutures similarly placed (including the periurethral muscular structures below) and two posterior sutures completed the anastomosis of the membranous urethra with a small ring into which the anterior portion of the margin of the vesical wound had been fashioned by the tying of the sutures, as shown in Figs. 8 and 9. The remainder of the vesical wound now presented a longitudinal opening which was easily closed by sutures (Fig. 8), thus completely closing the defect and replacing the prostatic urethra with a funnel-shaped process made by the bladder wall. The sutures used were silk, one end of each being left long and brought out of the wound so that they could be extracted later (since then I have found alternate sutures of catgut and silkworm gut, also left long, the best). After light gauze packing had been placed in various portions of the wound, the levator ani muscles were drawn together with catgut (two sutures) in front of the rectum and the skin wound closed on each side with interrupted catgut sutures, leaving only a small portion open at the angle in front for exit of the gauze drainage. The rubber catheter (which was of considerable service in making the anastomosis of the urethra and bladder) was fastened in place by adhesive plaster around the penis, and the patient was returned to the ward. During the operation he received 1,000 c.c. salt solution infusion beneath the breast, and his condition throughout was good, the pulse varying from 62 to 92 and being 80 at the end of the operation, which required two hours.

Examination of Tumor.-A study of the specimen removed showed adenocarcinoma involving the entire prostate, the region between the seminal vesicles and the inferior surface of the excised trigone and the vasa deferentia. The capsule of the prostate and the bladder at the upper limit of the excision were free.

Convalescence.-The patient made a good recovery. The perineal wound healed tight; there was no difficulty in urination; he was able to hold urine for three or four hours at night; there was incontinence during the day.

\section{REMARKS ON OPERATION.}

As remarked above, this radical operation has been performed on six patients with one operative death. The autopsy in this case showed extensive intraperitoneal metastases and explained the cause of death. Two patients have died since the operation, one a year later from an operation for vesical calculi. Autopsy showed a small carcinamatous mass about the size of a pea adjacent to the left vas deferens. This was the only cancerous tissue found; no metastatic glands or osseous metastases were made out. The recurrence had been predicted in this case after a study of the operative specimen which showed carcinoma near the upper end of the left seminal vesicle.

The other patient died of nephritis two months after the operation. Autopsy showed that the cancer had been thoronghly extirpated, a careful search failing to reveal any malignant disease, regionary or metastatic. Numerous sections were made of the pelvic tissues. It therefore secmed evident that had the man lived he would have remained cured of the cancer.

Three patients are living and well--one ten months, one eight months and one one montl after the operation. One patient has control over his urine and can hold it several hours; ons has incontinence in the day, but perfect control at night; the third is still in the hospital. All have becn completely relieved of the severe pain from which they suffered before operation. None of my cases were particularly early ones. With an early diagnosis and operation the operative mortality should be nil, as only the patient with extensive (unrecognized) peritoneal metastases showed any shock.

\section{CONCLUSION.}

Cancer of the prostate is quite a common disease, about one case in seven of prostatic enlargements in men 
past fifty being cancerous. It is characterized by induration-often of stony hardness, and pain is frequently present. The early diagnosis may be made when there is marked induration, and the absence of the usual intravesically projecting lobes, as shown by the cystoseope; (the prostatic orifice often appears normal). The disease is often of slow growth and remains for a long time confined within the limits of the firm prostatic capsule. 'The operation carricl out by me in six cases is necessary if a cure is to be expected; it is not difficult of performance, and furnishes remarkably satisfactory functional results. With early diagnosis the mortality should be nil and the percentage of cures large. The general practitioner should suspect every indurated enlarged prostate and the paticnt should be urged to submit to a perineal operation, when, if the disease is proved to be malignant, the radical operation can be done.

THE TREATMENT OF ANEURISM BY DIRECT, GRADUAI, ARTERIAI, CLOSURE.

REPORT ON AIIE APPLICATION OF THE METHOD TO A CASE OF ANEURISA OF TIIE ABDOMINAL AORTA.* ROBERT T. STRATTON, M.D.

Surgeon to the Receiving and to the Fabiola Irospitals. OAKLAND, CAL.

DATLNALE OF TREATMENT.

The main busis for the suggestion of gradual arterial closure as a probable means of relief for certain cases of aneurism lies in three facts óbserved in human pathology and surgical experience:

1. Gradual closure of a large blood vessel as from the pressure of a growing tumor, so far as such pressure is concerned, is not associated with depression of vital functions nor with nutritional or other disturbances within the area of its distribution. The anastomotic current is so gradually and perfectly established that the entire absence of symptoms due to circulatory disturbances may fail even to suggest the occlusion of a large blood vessel.

2. In the larger proportion of those exceptional cases of aneurism in which a spontaneous cure occurs this results from the deposition of the laminated coagulum or so-called active clot, on the walls of the sac, and is caused by the slowing and not the complete stoppage of the blood current in the vessel (Ashurst). It may result from any accidental cause, such as the pressure of an enlarging tumor on the artery on the proximal side of the seat of discase.

3. Aside from the radical surgical procedures which undertake, where indicated, the complete exclusion of excision of the sac or its obliteration by arteriorzhaphy, the best results in the surgical treatment of this disease, have come from methods which aim at the slowing of the blood stream through the sac, and the production of an active clot-as, for instance, in the Hunterian ligationrather than the sudden and complete cessation of the blood flow and the production of coagulation en masse. Methods which cause the formation of the passive clot at best are only followed because anatomic and other local conditions prevent the adoption of procedures designed to secure the deposition of the stratified coagulum.

'These three basal propositions and the principles underlying them lave long been recognized. While brilliant results in many cases of aneurism, especially those involving the arteries of the extremities, have followed

* Read before the Alameda County (Cal.) Med. Assoc. the radical procedures referred to and which are not based on these principles, yet unfortunately, the proportion of those not amenable to this form of surgical treatment is large. 'The usual age of patients afflicted with the discase, their depressed local and general vitality, associated organic discase, the anatomic site of the aneurism, are factors which all too frequently demand the adoption of some less radical, even if less hopeful, method.

It is not to be contended that the very gradual arterial closure induced by certain pathologic processes can be reproduced by surgical means, but it is evident that the more closely these can be approximated, within reasonable limits, by the surgeon, the better will be his results both in the avoidance of risks of sudden closure and the certainty of cure by the formation of an active coagulum.

In this connection it will be of interest to refer again to cases of spontancous cure by accidental slowing of the blood stream. Recoveries from this cause may result in the entire obliteration of the sac, the circulation being carriod on by means of collateral vessels, or
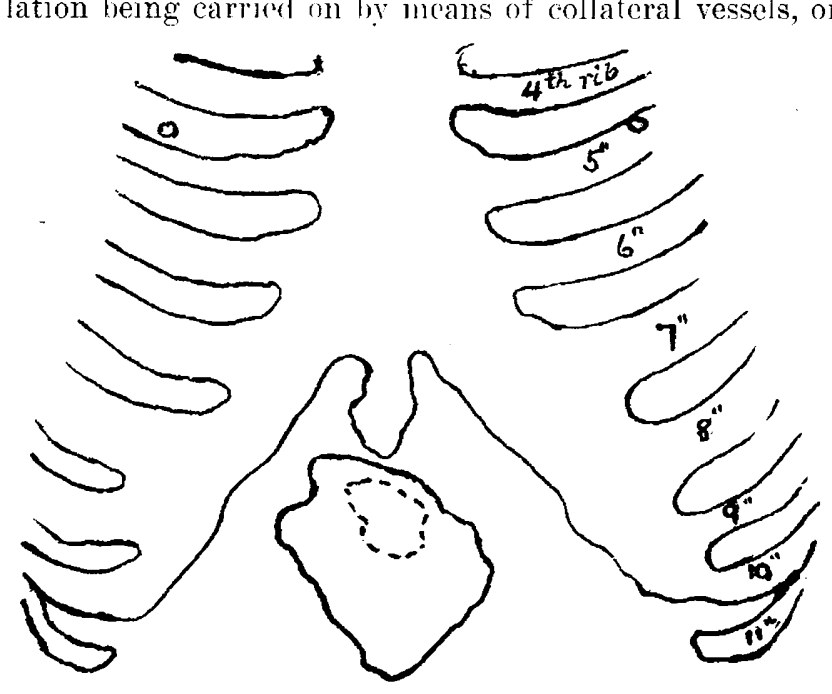

\section{I umbilicus.}

Fig. 1.-Reproduction from a tracing of outlines marked on the patient's thorax and abdomen. Dotted line indicates area of aneurismal pulsation detected by light palpation; solid line, limits of aneurismal pulsation outlined by moderately deep palpation.

a narrow channel may be left running through the tumor through which the circulation may be maintained. The recognition of the possibility of cure by the latter means is of great importance in relation to the successful treatment of aneurisms from the sac of which, or from their immediate neighborhood, arteries originate supplying vital organs and which have only very meager collateral circulatory channels. 'Thus, in an aneurism of the abdominal aorta from which arises the celiac axis, it is manifestly impossible to adopt any radical method of cure, and what degree of relief is ever obtained must be secured, it would seem, without the sacrifice of the lumen of this branch, for the reason that its subdivisions supply the stomach, spleen and liver and have only the slightest and most indirect collateral circulatory channels. It is thus evident that in such a case the method of cure must aim at the aroidance of the complete obliteration of the sac and the process of clot formation must be carried, if possible, only so far as to stop expansile pulsation, and to leave permanent channels through the sac, maintaining the patency of the larger arterial branches arising from the wall of the 